\title{
Comparative Circulatory Effects of Isoproterenol and Dopamine in Lambs with Experimental Cyanotic Heart Disease
}

\author{
DANIEL BERNSTEIN AND CHARLES CRANE
}

Department of Pediatrics, Stanford University, Stanford, California 94305

\begin{abstract}
To determine whether the hemodynamic responses to adrenergic agonists are altered during chronic hypoxemia secondary to an intracardiac right to left shunt, we studied seven lambs with surgically created pulmonic stenosis and atrial septal defect and nine controls during infusions of isoproterenol at 0.1 and $0.5 \mu \mathrm{g} / \mathrm{kg} / \mathrm{min}$ and dopamine at 5 and $20 \mu \mathrm{g} / \mathrm{kg} / \mathrm{min}$. Isoproterenol increased heart rate by $89 \pm 17 \%$ in control but only $46 \pm 6 \%$ in experimental lambs $(p<0.05)$. However, because resting heart rate was higher in experimental lambs $(213 \pm 7$ versus $177 \pm 12$ beats $/ \mathrm{min}, p<0.05$ ), maximal heart rates were similar $(310 \pm 7$ versus $326 \pm 6$ beats $/ \mathrm{min}$; NS). Cardiac output increased during isoproterenol from $219 \pm$ 20 to $425 \pm 54 \mathrm{~mL} / \mathrm{min} / \mathrm{kg}$ in experimental lambs $(p<$ $0.05)$ and, similarly, from $180 \pm 20$ to $425 \pm 71$ in controls ( $p<0.05$ ) (experimental versus control; NS). Dopamine also increased cardiac output similarly in both groups, at both doses, but without changing heart rate. Isoproterenol did not alter aortic oxygen saturation and increased systemic oxygen transport more than oxygen consumption. In contrast, dopamine at both doses decreased aortic oxygen saturation in experimental lambs (rest, $71 \pm 2 \%$ versus dopamine, $59 \pm 2 \% ; p<0.05$ ). With dopamine, the increase in systemic oxygen transport was equalled by an increase in oxygen consumption. Thus, circulatory responses to isoproterenol are similar in lambs with experimental cyanotic heart disease and controls, although higher resting heart rate in the experimental lambs reduces chronotropic reserve. Circulatory responses to dopamine are different, mainly due to the decrease in oxygen saturation in the experimental lambs. Inasmuch as the oxygen cost/ benefit ratio of adrenergic agonists may be altered by chronic hypoxemia and associated hemodynamic abnormalities, further evaluation of this ratio in hypoxemic human infants receiving these agents is indicated. (Pediatr Res 29: 323-328, 1991)
\end{abstract}

Myocardial performance and reserve may be decreased in infants and children with chronic hypoxemia secondary to cyanotic congenital heart disease $(1,2)$. This decrease in myocardial performance may be secondary to the direct effects of hypoxemia on myocardial contractility $(3,4)$, chronic hemodynamic deangements such as right ventricular outflow tract obstruction $2,5-8)$, or alterations in sympathetic nervous system regulation of myocardial function (9). During chronic hypoxemia, data sbtained in the newborn lamb and in other animal models

Received June 18, 1990; accepted November 16, 1990.

Correspondence and reprint requests: Daniel Bernstein, M.D., Department of 'ediatrics, Stanford University, Stanford, CA 94305.

Supported by a FIRST Award (D.B.) from the National Institutes of Health HL38741). suggest a chronic increase in sympathetic tone: a sustained increase in heart rate (10), a redistribution of blood flow away from peripheral vascular beds (11), elevated levels of circulating catecholamines $(9,12)$, and a down-regulation of the myocardial $\beta$-adrenergic receptor/adenylate cyclase system $(9,13,14)$. This increase in sympathetic tone could decrease myocardial reserve by attenuating the effects of further acute increases in sympathetic stimulation, either due to endogenous catecholamine release or to exogenous catecholamine administration.

Exogenously administered catecholamines may be of use during chronic hypoxemia because of their ability to increase systemic oxygen transport by $\beta$-adrenergic-mediated increases in heart rate and contractility; however, they can also increase systemic oxygen consumption by stimulating peripheral metabolism $(15,16)$. Agents with predominantly $\beta$-adrenergic effects may increase right to left shunting by decreasing peripheral vascular resistance, whereas agents with predominantly $\alpha$-adrenergic effects may decrease myocardial performance by increasing systemic vascular resistance (17). Whereas the general hemodynamic effects of these agents have been previously studied in both normoxic $(18,19)$ and acutely hypoxemic newborns $(20)$, it is not known whether chronic hypoxemia alters the hemodynamic responses to those agents. Thus, the purpose of our present study was to determine whether the general hemodynamic responses to two commonly used adrenergic agonists were attenuated during chronic hypoxemia secondary to an intracardiac right to left shunt. We also sought to determine whether chronic hypoxemia alters the oxygen cost/benefit ratios of these adrenergic agents.

\section{MATERIALS AND METHODS}

Preparation. Chronic hypoxemia was produced in seven newborn lambs using a model of cyanotic congenital heart disease developed by Teitel et al. (10). Briefly, surgery was performed on newborn lambs of mixed Western breed during the 1st week of life. Polyvinyl catheters were inserted via a hind leg pedal artery and vein and advanced into the descending aorta and inferior vena cava. Under general anesthesia, a thoracotomy was performed in the 4 th left intercostal space. Polyvinyl catheters were inserted into the ascending aorta, superior vena cava, right ventricle, pulmonary artery, and left atrium. A $5 \mathrm{~F}$ Fogarty dilation catheter (American Edwards Laboratories, Irvine, CA) was inserted via the hind leg pedal vein and advanced by direct visualization into the left atrium. A balloon atrial septostomy was then performed. The atrial septal defect was sized by passing the partially inflated balloon catheter across the defect and additional septostomies were performed if necessary. Next, an inflatable silicone rubber balloon occluder with polyvinyl tubing was placed around the main pulmonary artery. This balloon occluder was left deflated during the immediate postoperative period and in this state was nonrestrictive. All catheters were filled with heparin, plugged, and brought to the skin via a s.c. 
tunnel and were protected by a zippered vest worn by the lamb. The lambs were then returned to their cages and bottle-fed throughout the study period. The intravascular catheters were flushed with saline and reheparinized daily during the 2-wk study period. Antibiotics (Dual-Pen; Tech America, Kansas City, MO) were given intramuscularly immediately before each catheter flushing. Intramuscular iron dextran complex (equivalent to 100 $\mathrm{mg}$ of elemental iron) was given weekly to avoid the hemodynamic effects of iron deficiency.

After the lambs recovered for $3 \mathrm{~d}$, hypoxemia was produced by gradually inflating the pulmonary arterial occluder balloon with saline, which partially obstructed the right ventricular outflow tract and induced atrial right to left shunting. The details of this gradual inflation procedure have been published previously (10). Aortic oxygen saturation was measured by hemoximeter (OSM3; Radiometer, Copenhagen, Denmark). By adjusting the degree of balloon inflation, aortic oxygen saturation was decreased to 60 to $74 \%$ and was maintained at this level for $2 \mathrm{wk}$. Nine additional lambs also underwent thoracotomies and placement of intravascular catheters but did not have atrial septostomies or balloon occluders placed and served as normoxemic controls.

Hemodynamic protocol. The study protocol was performed after $2 \mathrm{wk}$ of hypoxemia in the seven experimental lambs and at approximately $4 \mathrm{wk}$ of age in the nine control lambs. The lambs were studied in a nonsedated, resting state. They were blindfolded and placed in a supporting sling in a room warmed to maintain a constant environmental temperature between 24 and $27^{\circ} \mathrm{C}$. Aortic, right and left ventricular, pulmonary arterial, left atrial, and central venous pressures were recorded on a Gould eightchannel direct writing recorder (Gould Instruments, Oxnard, $\mathrm{CA})$. Aortic and pulmonary arterial $\mathrm{Hb}$ concentrations and oxygen saturations were measured on a Radiometer OSM 3 hemoximeter. Arterial blood gases were measured on a Corning $168 \mathrm{pH} /$ blood gas analyzer (Corning, Medfield, MA). Cardiac output was measured by injection of $15-\mu \mathrm{m}$ diameter radionuclide-labeled microspheres (labeled with one of the following radionuclides: ${ }^{153} \mathrm{Gd},{ }^{57} \mathrm{Co},{ }^{114} \mathrm{In},{ }^{51} \mathrm{Cr},{ }^{113} \mathrm{Sn},{ }^{85} \mathrm{Sr},{ }^{95} \mathrm{Nb},{ }^{54} \mathrm{Mn}$, or ${ }^{65} \mathrm{Zn}$ ) into the left atrium while reference blood samples were withdrawn continuously and simultaneously from the ascending and descending aortic catheters into preweighed syringes for 1.5 $\mathrm{min}$ at a rate of $4 \mathrm{~mL} / \mathrm{min}(21)$.

Hemodynamic measurements were made at rest and after 10 min of continuous i.v. infusion of isoproterenol at $0.1 \mu \mathrm{g} / \mathrm{kg} /$ $\mathrm{min}$. The rate of infusion of isoproterenol was then increased to $0.5 \mu \mathrm{g} / \mathrm{kg} / \mathrm{min}$ and measurements repeated after $10 \mathrm{~min}$ of equilibration. These doses of isoproterenol were chosen to produce both submaximal and maximal isoproterenol-stimulated increases in heart rate and cardiac output. This was determined from pilot experiments in three hypoxemic and three control lambs during graded infusions of isoproterenol from 0.05 to 1.0 $\mu \mathrm{g} / \mathrm{kg} / \mathrm{min}$. In five experimental lambs and eight controls, a recovery period of at least $90 \mathrm{~min}$ was allowed after which a second set of resting measurements was performed. Hemodynamic measurements were then performed in a similar fashion during infusions of dopamine at 5 and $20 \mu \mathrm{g} / \mathrm{kg} / \mathrm{min}$. The lower dose of dopamine was chosen to produce predominantly $\beta$ adrenergic effect and the higher dose a combination of $\alpha$ - and $\beta$ adrenergic effect. During the study, estimated blood loss was replaced with fresh whole blood in all lambs. At the end of the study, the lambs were killed and dissected.

Calculations. Total cardiac output was calculated by dividing total recovered radioactivity counts by reference blood flows (21). To correct for potential atrial left to right shunting of microspheres in the hypoxemic lambs, recovered counts from the lungs were examined. If lung counts were greater than 2 SD above control values, the difference was subtracted from the total recovered counts. This correction was performed in two of the seven hypoxemic lambs; however, it did not alter the statistical significance of any of the results. Stroke volume was calculated as cardiac output divided by heart rate. Aortic and pulmonary arterial oxygen contents were calculated as the product of the simultaneously obtained $\mathrm{Hb}$ concentration, $\mathrm{Hb}$ oxygen saturation, and a $\mathrm{Hb}$ oxygen-binding capacity of $1.36 \mathrm{~mL}$ oxygen/dL. Systemic vascular resistance was calculated as the difference between aortic mean pressure and central venous pressure divided by cardiac output. Systemic oxygen transport was calculated as the product of cardiac output and aortic oxygen content. Systemic oxygen consumption was calculated as the product of cardiac output and the arteriovenous oxygen content difference. Pulmonary blood flow was then calculated by the Fick formula as the systemic oxygen consumption divided by the pulmonary arteriovenous oxygen content difference. Because of the atrial right to left shunt in the experimental lambs, we utilized an assumed pulmonary venous oxygen saturation of $95 \%$, based on the mean systemic level of oxygen saturation in the control lambs. Right to left shunt was then calculated as systemic blood flow minus effective pulmonary blood flow.

Statistical analysis. Data were compared between each of the resting states and each level of agonist infusion using analysis of variance and Fisher's protected least significant difference multiple range testing. Data were also compared between the experimental and control lambs and between isoproterenol and dopamine during each condition using an unpaired $t$ test. Results are expressed as the mean \pm 1 SEM. Statistical significance was considered to be achieved when $p$ was $<0.05$.

\section{RESULTS}

General characteristics. There was no significant difference in age at study between experimental and control lambs (Table 1). The experimental lambs weighed less than the control lambs, a failure of growth previously described in this model of chronic hypoxemia (10). Although arterial oxygen saturation was decreased by $20 \%$ in the experimental lambs compared with controls, arterial oxygen content returned to control level because of the increase in $\mathrm{Hb}$ concentration in the experimental lambs (Table 1).

Determinants of cardiac output. In the experimental lambs, isoproterenol at both 0.1 and $0.5 \mu \mathrm{g} / \mathrm{kg} / \mathrm{min}$ resulted in lesser increases in heart rate than in controls (Fig. 1 $A$ ). However, because resting heart rate was higher in the experimental lambs, maximal heart rates were similar (Fig. $1 B$ ). Neither dose of isoproterenol resulted in significant increases in stroke volume in either group of lambs (Fig. $1 C$ and $D$ ). Thus, in the experimental lambs, the increase in cardiac output with isoproterenol was not different from that in the controls (Fig. $1 E$ and $F$ ), and the mechanism for this increase in cardiac output was the increase in heart rate.

Dopamine at either 5 or $20 \mu \mathrm{g} / \mathrm{kg} / \mathrm{min}$ did not change heart rate in either group of lambs (Fig. $2 A$ and $B$ ). Stroke volume increased, reaching statistical significance only at $20 \mu \mathrm{g}$ of dopamine (Fig. $2 D$ ), and this response was identical in experimental and control lambs (Fig. $2 C$ and $D$ ). Thus, dopamine also resulted in similar increases in cardiac output in experimental and control lambs (Fig. $2 E$ and $F$ ); however, the mechanism for this increase in cardiac output was the increase in stroke volume.

Pressures and systemic vascular resistance. With isoproterenol, there were no significant differences in aortic systolic or mean pressures in either group of lambs (Table 2). With dopamine at

Table 1. Characteristics of chronically hypoxemic lambs compared with controls by t test

\begin{tabular}{lclc}
\hline & Control & Hypoxemic & $p$ \\
\hline Age $(\mathrm{d})$ & $24.7 \pm 0.7$ & $27.7 \pm 1.6$ & $\mathrm{NS}$ \\
Weight $(\mathrm{kg})$ & $8.23 \pm 0.54$ & $6.96 \pm 0.41$ & $<0.1$ \\
Aortic $\mathrm{O}_{2}$ saturation $(\%)$ & $93.7 \pm 1.4$ & $74.7 \pm 2.0$ & $<0.0001$ \\
Aortic $\mathrm{Hb}(\mathrm{g} / \mathrm{dL})$ & $9.2 \pm 0.5$ & $11.4 \pm 0.5$ & $<0.01$ \\
Aortic $\mathrm{O}_{2}$ content $(\mathrm{mL} / \mathrm{dL})$ & $11.6 \pm 0.6$ & $11.6 \pm 0.7$ & $\mathrm{NS}$ \\
\hline
\end{tabular}


A

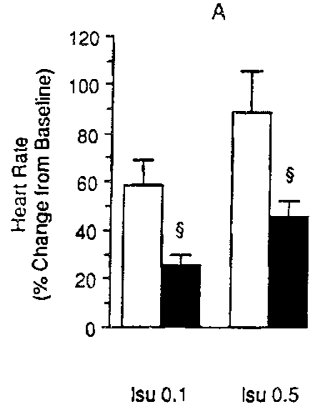

$B$

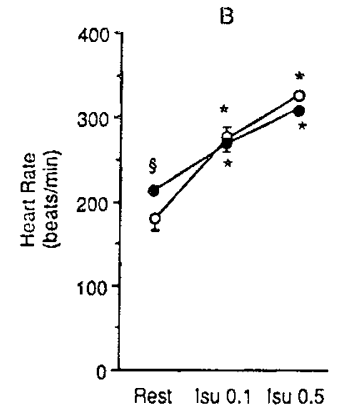

c

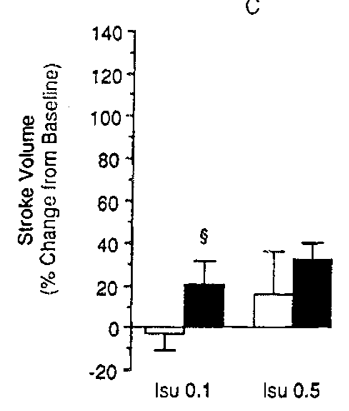

D

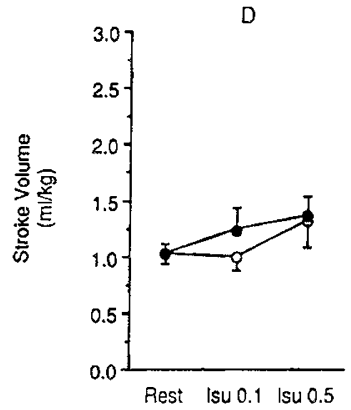

E
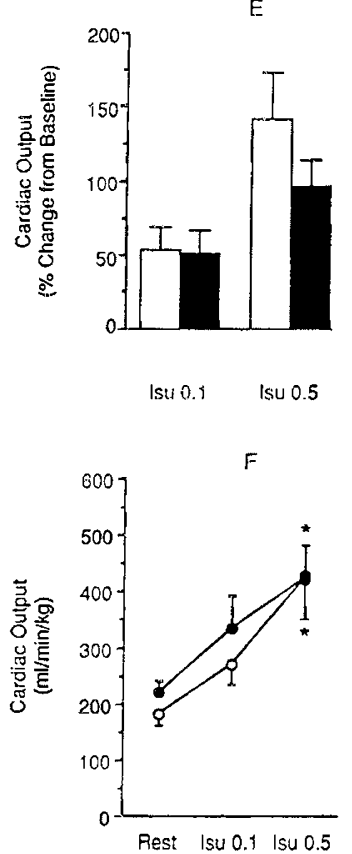

Fig. 1. Effect of infusions of isoproterenol $(I s u ; 0.1$ and $0.5 \mu \mathrm{g} / \mathrm{kg} / \mathrm{min})$ on heart rate $(A$ and $B)$, calculated stroke volume $(C$ and $D)$, and cardiac output $(E$ and $F)$ in control $(O)$ and experimental $(\bullet)$ lambs. The upper panels show percent changes from baseline and the lower panels absolute values. ${ }^{*} p<0.05$ vs rest by analysis of variance; $\S p<0.05$ experimental $v s$ control by $t$ test.
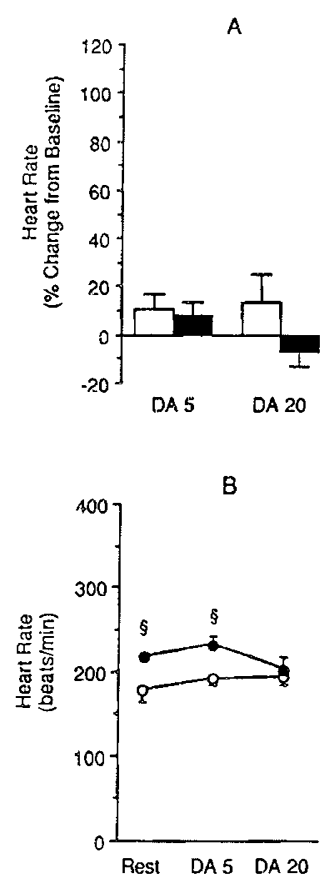

C

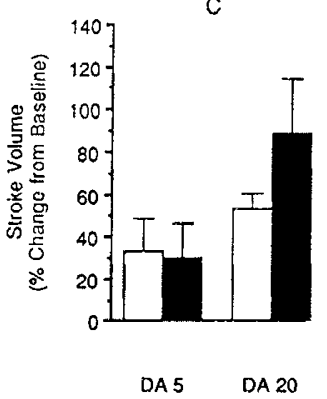

D

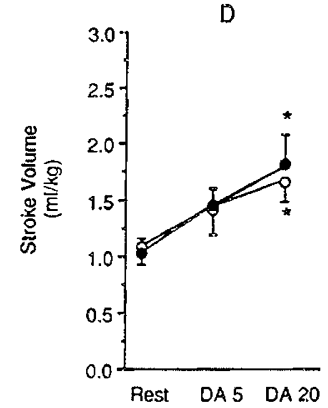

E.

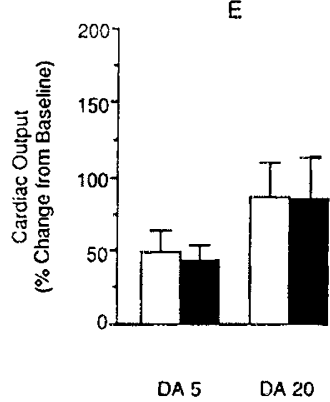

F

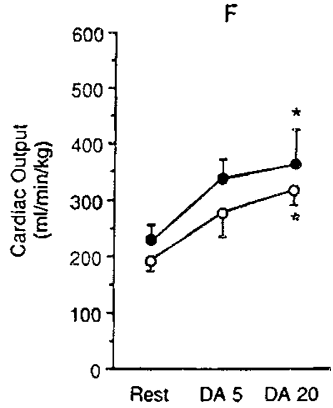

Fig. 2. Effect of infusions of dopamine $(D A ; 5$ and $20 \mu \mathrm{g} / \mathrm{kg} / \mathrm{min})$ on heart rate $(A$ and $B)$, calculated stroke volume $(C$ and $D)$, and cardiac output $(E$ and $F)$ in control $(O)$ and experimental $(\bullet)$ lambs. ${ }^{*} p<0.05$ vs rest by analysis of variance; $\S p<0.05$ experimental vs control by $t$ test.

$20 \mu \mathrm{g} / \mathrm{kg} / \mathrm{min}$, systolic pressure increased in the experimental lambs $(p<0.05)$. Aortic diastolic pressure decreased significantly at $0.5 \mu \mathrm{g} / \mathrm{kg} / \mathrm{min}$ of isoproterenol in both experimental and control lambs. Left atrial pressures were not significantly changed by either drug in either experimental or control lambs. Systemic vascular resistance declined with both isoproterenol and dopamine in both groups of lambs. Comparing the two drugs, aortic mean pressures were significantly lower with isoproterenol than with dopamine in both groups of lambs ( $p<0.05$ by $t$ test) and the decline in systemic vascular resistance with isoproterenol was greater than that with dopamine in the control lambs $(p<0.01)$.

Oxygenation. Isoproterenol did not alter aortic oxygen satu- ration in the experimental lambs (Fig. $3 A$ ). In contrast, dopamine decreased aortic oxygen saturation by $17 \%$ in the experimental lambs $(p<0.05)$. In the experimental lambs, mixed venous oxygen saturation was significantly lower with dopamine than with isoproterenol $(p<0.001)$. In the experimental lambs, the increase in pulmonary blood flow with dopamine was proportionately less than the increase in systemic blood flow (Fig. 4A). Thus, there was a decrease in the pulmonary to systemic blood flow ratio with dopamine (Fig. $4 B$ ), increasing the right to left shunt $(p<0.05)$.

In both groups of lambs, $0.5 \mu \mathrm{g} / \mathrm{kg} / \mathrm{min}$ of isoproterenol increased systemic oxygen transport, whereas $20 \mu \mathrm{g} / \mathrm{kg} / \mathrm{min}$ of 
Table 2. Aortic and left atrial blood pressures in control and chronically hypoxemic lambs*

\begin{tabular}{|c|c|c|c|c|c|c|}
\hline & Rest 1 & Isu 0.1 & Isu 0.5 & Rest 2 & DA 5 & DA 20 \\
\hline \multicolumn{7}{|l|}{ Aortic systolic } \\
\hline Control & $105 \pm 4$ & $96 \pm 7$ & $96 \pm 7$ & $107 \pm 5$ & $112 \pm 5$ & $122 \pm 7$ \\
\hline Hypoxemic & $114 \pm 7$ & $121 \pm 7$ & $121 \pm 10$ & $116 \pm 5$ & $116 \pm 5$ & $138 \pm 5 \dagger$ \\
\hline \multicolumn{7}{|l|}{ Aortic diastolic } \\
\hline Control & $68 \pm 4$ & $57 \pm 6$ & $54 \pm 5 \dagger$ & $70 \pm 4$ & $73 \pm 5$ & $67 \pm 6$ \\
\hline Hypoxemic & $59 \pm 2$ & $58 \pm 3$ & $50 \pm 3 \dagger$ & $62 \pm 5$ & $57 \pm 4$ & $65 \pm 4$ \\
\hline \multicolumn{7}{|l|}{ Aortic mean } \\
\hline Control & $80 \pm 4$ & $69 \pm 5$ & $68 \pm 5 \ddagger$ & $82 \pm 4$ & $85 \pm 5$ & $86 \pm 5 \ddagger$ \\
\hline Hypoxemic & $74 \pm 2$ & $75 \pm 3$ & $71 \pm 4 \ddagger$ & $77 \pm 4$ & $72 \pm 5$ & $87 \pm 5 \ddagger$ \\
\hline \multicolumn{7}{|l|}{ Left atrial mean } \\
\hline Control & $2 \pm 1$ & $2 \pm 1$ & $4 \pm 1$ & $2 \pm 1$ & $3 \pm 1$ & $4 \pm 1$ \\
\hline Hypoxemic & $1 \pm 1$ & $2 \pm 1$ & $2 \pm 1$ & $2 \pm 1$ & $1 \pm 1$ & $2 \pm 1$ \\
\hline \multicolumn{7}{|c|}{$\begin{array}{l}\text { Systemic vascular resist- } \\
\text { ance }\end{array}$} \\
\hline Control & $0.47 \pm 0.05$ & $0.28 \pm 0.03 \dagger$ & $0.17 \pm 0.02 \dagger \ddagger$ & $0.43 \pm 0.04$ & $0.34 \pm 0.04$ & $0.27 \pm 0.02 t+$ \\
\hline Hypoxemic & $0.35 \pm 0.05$ & $0.24 \pm 0.03 \dagger$ & $0.17 \pm 0.02 \uparrow$ & $0.35 \pm 0.05$ & $0.22 \pm 0.05$ & $0.25 \pm 0.08$ \\
\hline
\end{tabular}

* Isu, isoproterenol; DA, dopamine.

$\dagger p<0.05 v s$ rest by analysis of variance and Fisher's protected least significant difference test.

$\ddagger p<0.05$ isoproterenol $v s$ dopamine by $t$ test.

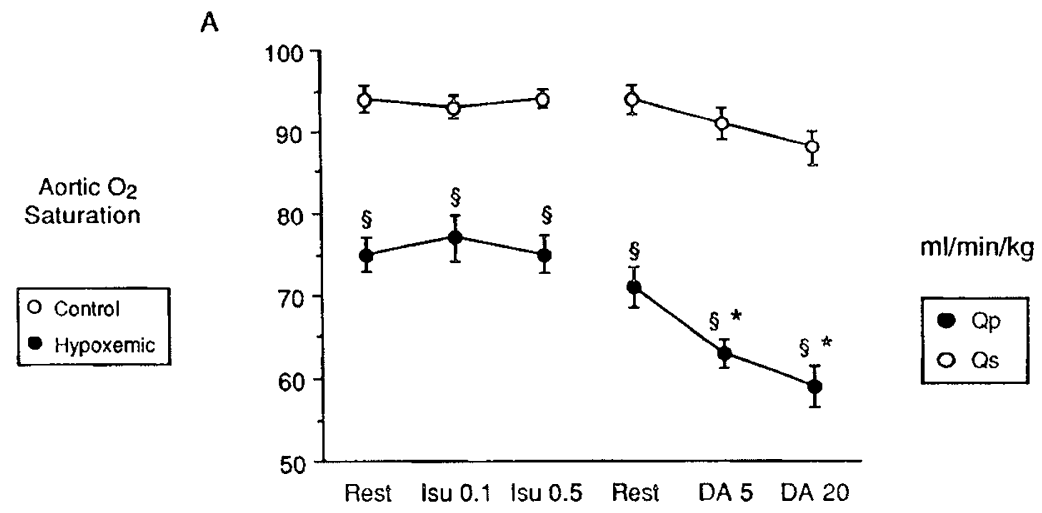

B

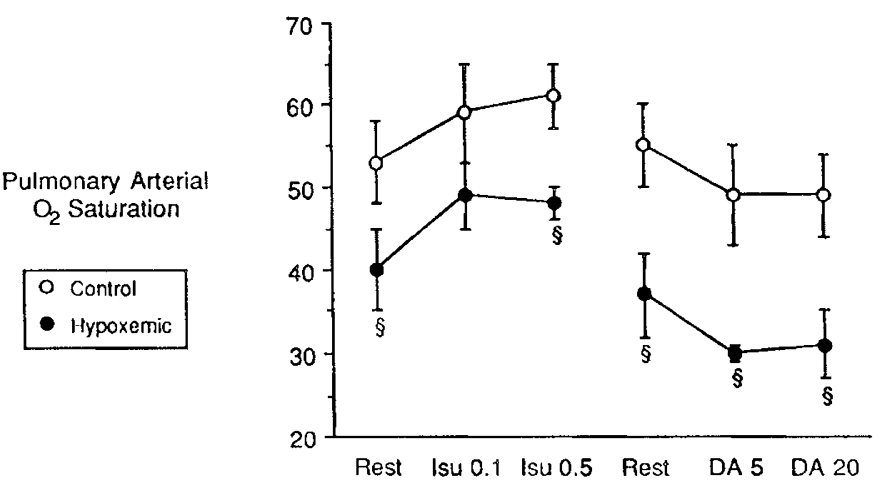

Fig. 3. Aortic $(A)$ and pulmonary arterial $(B)$ oxygen saturations in experimental and control lambs during infusions of isoproterenol $(I s u)$ and dopamine $(D A){ }^{*} p<0.05$ vs rest by analysis of variance; $\S p<0.05$ experimental $v s$ control by $t$ test.

dopamine increased systemic oxygen transport only in the control lambs (Fig. $5 A$ ). The two drugs, however, had equal effects on systemic oxygen consumption (Fig. $5 B$ ). Thus, in the experimental lambs given isoproterenol, oxygen transport increased more than did oxygen consumption, so that fractional extraction of oxygen (oxygen consumption divided by oxygen transport) decreased (Fig. $5 C$ ). With dopamine, the increase in oxygen transport was equalled by the increase in oxygen consumption so that fractional extraction was unchanged. This difference in fractional extraction of oxygen between isoproterenol and do-
A

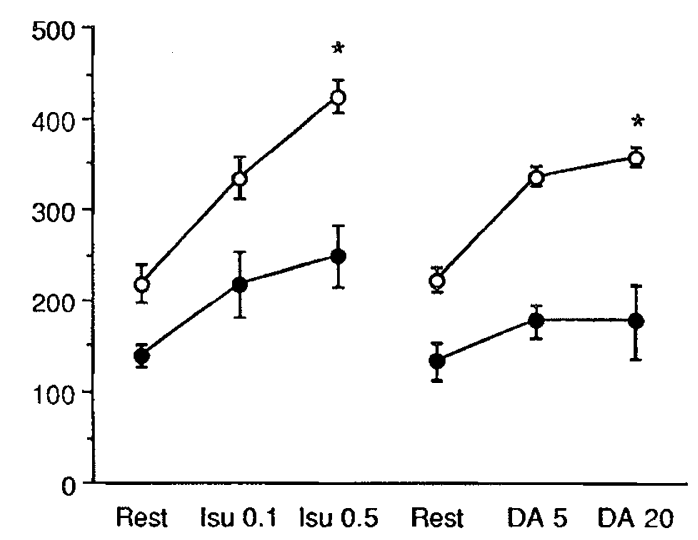

B

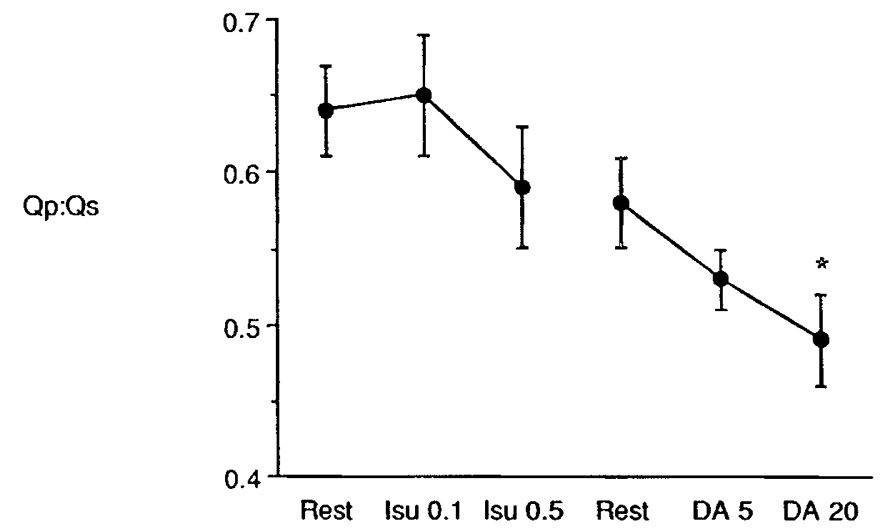

Fig. 4. Systemic and pulmonary blood flows $(A)$ and pulmonary to systemic blood flow ratio $(Q p: Q S)(B)$ in experimental lambs during infusions of isoproterenol $(I s u)$ and dopamine $(D A) .{ }^{*} p<0.05 v s$ rest by analysis of variance.

pamine reached statistical significance only for the experimental lambs $(p=0.03)$.

\section{DISCUSSION}

The results of our study demonstrate that the newborn lamb with experimental cyanotic heart disease is capable of a normal 

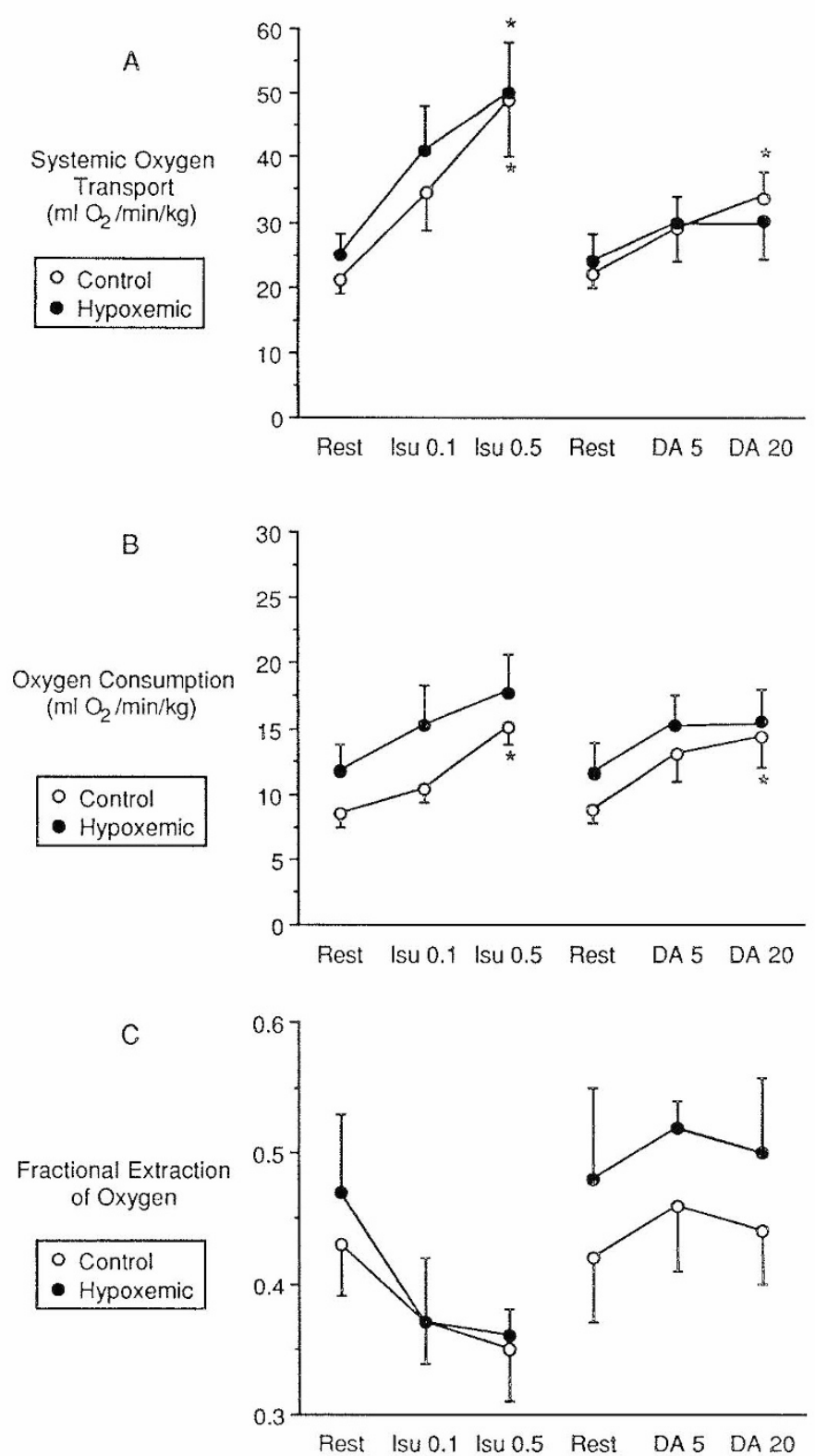

Fig. 5. Effects of isoproterenol (ISU) and dopamine $(D A)$ on indices of systemic oxygenation in experimental and control lambs: $A$, systemic oxygen transport; $B$, oxygen consumption; $C$, fractional extraction of oxygen (the ratio of oxygen consumption to systemic oxygen transport). ${ }^{*} p<0.05$ vs rest by analysis of variance.

cardiac output response to exogenously administered adrenergic agonists. This occurs despite evidence of an increase in sympathetic tone and a decrease in left ventricular $\beta$-adrenergic receptor density (9). These results are, however, consistent with those reported during other states of increased sympathetic tone in the newborn. In both acutely hypoxemic lambs (20) and in newborn lambs with an aortopulmonary left to right shunt (22), previous investigators have also failed to demonstrate an attenuation of the cardiac output response to adrenergic agonists. It is possible that the increased baseline level of neurally mediated sympathetic stimulation common to all of these models $(9,20,22)$ may make the detection of abnormalities in response to infused catecholamines more difficult. Additionally, unlike patients with cardiomyopathy (23), in our model we find no evidence of depleted myocardial stores of norepinephrine (9). Finally, there may be sufficient signal amplification distal to the level of adenylate cyclase to attenuate the effects of $\beta$-receptor down-regulation.

Although there were many similarities between experimental and control lambs in their responses to adrenergic agonists, there were also some notable differences. Whereas cardiac output responses to isoproterenol were similar, the higher resting heart rate in the experimental lambs reduces chronotropic reserve. This is similar to the findings of Maher et al. (24) in adult dogs with chronic alveolar hypoxia. These authors also found a decrease in maximal heart rate response to isoproterenol, although the resting heart rates of Maher's dogs were not elevated. This may reflect a difference in species, developmental age, method of induction of hypoxemia, or myocardial vagal innervation between the two studies. In this regard, we have recently demonstrated that atrial muscarinic receptors are not altered in lambs with experimental cyanotic heart disease (25).

The heart rate and cardiac output responses to dopamine were also similar in the experimental and control lambs. Whereas isoproterenol increased cardiac output by increasing heart rate, dopamine increased cardiac output by increasing stroke volume. However, whereas isoproterenol did not alter aortic oxygen saturation, dopamine decreased aortic oxygen saturation in the experimental lambs. This reduction in systemic arterial oxygenation with dopamine has been described previously $(15,17,26)$ and ascribed to ventilation/perfusion abnormalities (17, 26), pulmonary vasoconstriction (27), and an increase in intrapulmonary shunting (28). In the current study, we measured pulmonary arterial pressures in two of the experimental lambs and found no evidence that an increase in pulmonary vascular resistance was responsible for the desaturation encountered in response to dopamine. Alternatively, in the presence of a right to left shunt, aortic oxygen content is determined by the relative volumes and saturations of shunt blood flow versus pulmonary blood flow. Mixed venous oxygen saturation was significantly lower with dopamine than with isoproterenol. Thus, with dopamine, the oxygen content of blood shunting right to left across the atrial septal defect was lower. Although both isoproterenol and dopamine increased the absolute volume of this right to left shunt, with dopamine the increase in pulmonary blood flow was proportionately less than the increase in systemic blood flow, as indicated by a marked decrease in pulmonary to systemic blood flow ratio. These factors would thus tend to decrease aortic oxygen saturation in the experimental lambs. Finally, it is likely that at least a portion of this saturation decrease is of pulmonary origin, as we also saw a small decrease in oxygen saturation in the control lambs. Although we did not measure indices of ventilation or pulmonary venous saturation directly, it has been previously demonstrated that dopamine is a potent depressor of the hypoxic ventilatory drive, possibly mediated by stimulation of dopaminergic $\mathrm{DA}_{2}$ receptors in the carotid body (29).

One potentially deleterious effect of catecholamine administration is the ability of these agents to increase systemic oxygen consumption $(15,16,30)$. In the current study, isoproterenol increased systemic oxygen transport to a greater extent than oxygen consumption in the experimental lambs. Thus, fractional extraction of oxygen, the ratio of oxygen demand to supply, decreased. With dopamine, the increase in oxygen transport was equalled by the increase in oxygen consumption so that fractional extraction of oxygen was unchanged. Thus, in the experimental lambs, isoproterenol improved oxygen economy, whereas the oxygen costs of dopamine equalled its beneficial effects on oxygen supply. Do these results suggest that isoproterenol is the preferred adrenergic agonist for the newborn with chronic hypoxemia? Because the newborn may have limited contractile reserve $(31-33)$, it has been suggested that agents with predominantly chronotropic effects may be more effective in increasing cardiac output in the newborn $(22,34,35)$. In the current study, isoproterenol, the agent with predominantly chronotropic effects, resulted in larger increases in cardiac output than did dopamine, the agent with predominantly inotropic effects. However, because these drugs can have variegate effects on myocardial oxygen consumption (36) and subendocardial perfusion (36-38), an assessment of the myocardial oxygen cost/benefit ratio of these 
agents must be performed before recommending a preferred adrenergic agonist in the setting of chronic hypoxemia.

It is unlikely that differences in circulating blood volume between the experimental and control lambs could have altered our results (39). Blood volume has been shown to be increased in chronically hypoxemic lambs (40); thus, drug delivery in the experimental lambs should have, if anything, been lower. To account for differences in drug delivery, we chose the higher dose of isoproterenol to be twice that required for maximal heart rate and cardiac output responses in a series of three pilot studies. Also, although it is possible that our results may have been affected by the order in which the two inotropic agents were administered, we waited a minimum of 90 min between studies and demonstrated a return to baseline hemodynamics before starting the infusion of dopamine. Finally, although we did not measure indices of myocardial contractility, neither preload, as measured indirectly by left atrial pressure, nor afterload, as measured by systemic pressures and vascular resistance, was significantly different between the two groups. Our study was not intended to address the issue of whether baseline contractility or contractile reserve is decreased in the newborn with chronic hypoxemia. Our study also does not attempt to isolate the effects of chronic hypoxemia from the additional hemodynamic, hematologic, and neurohumoral alterations present secondary to right ventricular outflow tract obstruction and atrial right to left shunting.

In conclusion, our data suggest that the newborn lamb with chronic hypoxemia secondary to experimental cyanotic heart disease is capable of a normal general hemodynamic response to adrenergic agonists. Whether baseline contractility is also normal or whether periods of hypoxemia longer than 2 wk might adversely affect the response to adrenergic agonists remains to be determined. Our data also suggest some potential advantages of isoproterenol over dopamine in the hypoxemic newborn. Inasmuch as we have demonstrated that the oxygen cost/benefit ratio of adrenergic agonists may be altered by chronic hypoxemia, further evaluation of this ratio in hypoxemic human infants receiving these agents is clearly indicated.

Acknowledgment. The authors would like to thank Ellen Voss for her technical assistance.

\section{REFERENCES}

1. Graham T, Erath H, Boucek R, Boerth R 1980 Left ventricular function in cyanotic congenital heart disease. Am J Cardiol 45:1231-1236

2. Jarmakani J, Graham T, Cevent R, Jewett $P 1972$ Left heart function in children with tetralogy of Fallot before and after palliative or corrective surgery. Circulation 46:478-490

3. Downing S, Talner N, Gardner T 1966 Influences of arterial oxygen tensions and $\mathrm{pH}$ on cardiac function in the newborn lamb. Am J Physiol 211:12031208

4. Walley K, Becker C, Hogan R, Teplinsky K, Wood L 1988 Progressive hypoxemia limits left ventricular oxygen consumption and contractility. Circ Res 63:849-859

5. Larson D, Womble J, Copeland J, Russell D, Shumway N 1982 Concurrent left and right ventricular hypertrophy in dog models of right ventricula overload. J Thorac Cardiovasc Surg 84:543-547

6. Ludbrook P, Byrne J, McKnight R 1979 Influence of right ventricular hemodynamics on left ventricular diastolic pressure-volume relations in man. Circulation 59:21-31

7. Visner M, Arentzen C, O'Connor M, Larson E, Anderson RW 1980 Septal encroachment on left ventricular systolic function during acute right ventricular pressure overload. Surg Forum 31:288-290

8. Olsen C, Tyson G, Maier G, Spratt J, Davis J, Rankin J 1983 Dynamic ventricular interaction in the conscious dog. Circ Res 52:85-104

9. Bernstein D, Voss E, Huang S, Doshi R, Crane C 1990 Differential regulation of right and left ventricular $\beta$-adrenergic receptors in experimental cyanotic heart disease in newborn lambs. J Clin Invest 85:69-74

10. Teitel D, Sidi D, Bernstein D, Heymann M, Rudolph AM 1985 Chronic hypoxemia in the newborn lamb: cardiovascular, hematopoietic, and growth adaptations. Pediatr Res 19:1004-1010

11. Bernstein D, Teitel D, Sidi D, Heymann M, Rudolph A 1987 Redistribution of regional blood flow and oxygen delivery in experimental cyanotic congenital heart disease. Pediatr Res 22:389-393

12. Cunningham W, Becker E, Kreuzer F 1965 Catecholamines in plasma and urine at high altitude. J Appl Physiol 20:607-610

13. Voelkel M, Hegstrand L, Reeves J, McMurty IF, Molinoff PB 1981 Effects of hypoxia on density of $\beta$-adrenergic receptors. J Appl Physiol: 50:363-366

14. Light K, Dick T, Hughes M 1984 Central and peripheral receptors in guineapigs exposed to simulated high altitude. Neuropharmacology 23:189-195

15. Abdul-Rasool I, Chamberlain J, Swan P, Ward D 1987 Cardiorespiratory and metabolic effects of dopamine and dobutamine infusions in dogs. Crit Care Med 15:1044-1050

16. Himms-Hagen J 1967 Sympathetic regulation of metabolism. Pharmacol Rey 19:367-461

17. Loeb H, Bredakis J, Gunnar R 1977 Superiority of dobutamine over dopamine for augmentation of cardiac output in patients with chronic low output cardiac failure. Circulation 55:375-381

18. Driscoll DJ, Gillette PC, Ezrailson EG, Schwartz A 1978 Inotropic response of the neonatal canine myocardium to dopamine. Pediatr Res 12:42-45

19. Driscoll DJ, Gillette PC, Lewis RM, Hartley CJ, Schwartz A 1979 Comparative hemodynamic effects of isoproterenol, dopamine, and dobutamine in the newborn dog. Pediatr Res 13:1006-1009

20. O'Laughlin MP, Fisher DJ, Dreyer WJ, Smith EO 1987 Augmentation of cardiac output with intravenous catecholamines in unanesthetized hypoxemic newborn lambs. Pediatr Res 22:667-674

21. Heymann M, Payne B, Hoffman J, Rudolph A 1977 Blood flow measurement with radionuclide-labelled particles. Prog Cardiovasc Dis 20:55-79

22. Toorop GP, Hardjowijono R, Dalinghaus M, Koers JH, Wildevuur CR, Zijlstra WG, Kuipers JR 1987 Comparative circulatory effects of isoproterenol, dopamine, and dobutamine in conscious lambs with and without aortopulmonary left-to-right shunts. Circulation 75:1222-1228

23. Bristow M, Ginsburg R, Minobe W, Cubicciotti R, Sageman A, Lurie K Billingham M, Harrison D, Stinson E 1982 Decreased catecholamine sensitivity and $\beta$-adrenergic-receptor density in failing human hearts. $N$ Engl $J$ Med 307:205-211

24. Maher J, Manchanda S, Cymerman A, Wolfe D, Hartley L 1975 Cardiovascular responsiveness to $\beta$-adrenergic stimulation and blockade in chronic hypoxia. Am J Physiol 228:477-481

25. Doshi R, Strandness E, Bernstein D 1990 Regulation of atrial adrenergic and muscarinic receptors during chronic hypoxemia. Pediatr Res 27:233A(abstr)

26. Worthley LI, Tyler P, Moran JL 1985 A comparison of dopamine, dobutamine and isoproterenol in the treatment of shock. Intensive Care Med 11:13-19

27. Mentzer Jr R, Alegre C, Nolan. SP 1976 The effects of dopamine and isoproterenol on the pulmonary circulation. $J$ Thorac Cardiovasc Surg 71:807-814

28. Rapin M, Lemaire F, Regnier B, Teisseire B 1977 Increase of intrapulmonary shunting induced by dopamine. Proc $\mathrm{R}$ Soc Med 70(suppl 2):71-75

29. Ward D, Bellville JW 1982 Reduction of hypoxic ventilatory drive by dopamine. Anesth Analg 61:333-337

30. Scott A, Chakrabarti M, Hall G 1979 Oxygen transport during dopamine infusion in dogs. Br J Anaesth 51:1011-1019

31. Romero T, Friedman W 1979 Limited left ventricular response to volume overload in the neonatal period: a comparative study with the adult animal. Pediatr Res 13:910-915

32. Teitel D, Sidi D, Chin T, Brett C, Heymann M, Rudolph A 1985 Developmental changes in myocardial contractile reserve in the lamb. Pediatr Res 19:948-955

33. Berman Jr W, Musselman J 1979 Myocardial performance in the newborn lamb. Am J Physiol 237:H66-H70

34. Zaritsky A, Chernow B 1984 Use of catecholamines in pediatrics. J Pediat 105:341-350

35. Driscoll D, Pinsky W, Entman M 1979 How to use inotropic drugs in children. Drug Ther 9:124-135

36. Ward HB, Einzig S, Wang T, Bianco RW, Foker JE 1984 Comparison of catecholamine effects on canine myocardial metabolism and regional blood flow during and after cardiopulmonary bypass. J Thorac Cardiovasc Surg $87: 452-465$

37. Vatner SF, Baig H 1979 Importance of heart rate in determining the effects of sympathomimetic amines on regional myocardial function and blood flow in conscious dogs with acute myocardial ischemia. Circ Res 45:793-803

38. McClenathan JH, Guyton RA, Breyer RH, Newman GE, Michaelis LL 1977 The effects of isoproterenol and dopamine on regional myocardial blood flow after stenosis of circumflex coronary artery. J Thorac Cardiovasc Surg 73:431-435

39. Manders W, Pagani M, Vatner S 1979 Depressed responsiveness to vasoconstrictor and dilator agents and baroreflex sensitivity in conscious, newborn lambs. Circulation 60:945-955

40. Dalinghaus M, Gerding A, Koers J, Gratama J, Kuipers J 1987 Extracellular body fluid volumes in chronically hypoxemic lambs. Pediatr Res 21:189A(abstr) 


\title{
Age-Dependent Effects of Sodium Nitroprusside and Dopamine in Lambs
}

\author{
CAROLYN E. GETMAN, BOYD W. GOETZMAN, AND STEPHEN BENNETT
}

Division of Neonatology, Department of Pediatrics, University of California, Davis, California 95616

\begin{abstract}
Vasodilators and cardiotonic agents are frequently used in hypoxemic newborn infants with persistent pulmonary hypertension. We studied the effects of sodium nitroprusside and dopamine on hypoxia-induced pulmonary hypertension in seven newborn (0-3 d) and seven young (10-14 d) lambs under chloralose anesthesia. Pulmonary blood flow, pulmonary arterial pressure, systemic arterial pressure, and left atrial pressure were measured during the experimental states of hypoxia, hypoxia plus nitroprusside, and hypoxia plus both nitroprusside and dopamine. Pulmonary and systemic arterial pressure and cardiac output all decreased significantly when hypoxemic newborn lambs were given nitroprusside; in contrast, when hypoxemic young lambs were given nitroprusside, cardiac output did not change, whereas both pulmonary and systemic arterial pressure decreased significantly. Calculated pulmonary vascular resistance was unchanged in the newborn lambs but fell in the young lambs, implying that active pulmonary vasodilation by nitroprusside occurred only in the latter group. Systemic vascular resistance was not significantly affected by nitroprusside in either group. The addition of dopamine resulted in qualitatively similar changes in both groups of lambs, with increased pulmonary blood flow and no significant change in pulmonary or systemic arterial pressures. Maturation in vascular smooth muscle responsiveness to nitrovasodilators may explain the age-related differences that we found in lambs, and could also account for the variable clinical responses to vasodilators observed in hypoxemic human infants. (Pediatr Res 29: 329-333, 1991)
\end{abstract}

\section{Abbreviations}

SNP, sodium nitroprusside

EDRF, endothelium-derived relaxing factor bpm, beats per min

SNP is sometimes used as a vasodilator in neonates with persistent pulmonary hypertension, severe respiratory distress syndrome, or cardiac failure. Although nitroprusside has been extensively studied in adult humans and animals, its effects in newborn humans and animals are less well documented. The drug appears to be a nonselective vasodilator, inasmuch as differential effects on the pulmonary and systemic circulation have not been shown. This may be responsible for its unpredictable clinical effects when used for treatment of persistent pulmonary hypertension of the newborn (1-3). In addition, because hypotension is a frequent clinical side effect of nitroprusside, an inotrope such as dopamine may be added in attempt to augment cardiac output and maintain systemic blood pressure.

Received October 18, 1989; accepted December 4, 1990

Correspondence and reprint requests: Boyd W. Goetzman, M.D., Ph.D., U.C. Davis, Division of Neonatology, TB-193, Davis, CA 95616.
The purpose of this study was: 1 ) to evaluate the effects of nitroprusside and dopamine on the pulmonary and systemic circulation in a lamb model of hypoxia-induced pulmonary hypertension and 2) to determine age-related differences in response to these agents.

\section{MATERIALS AND METHODS}

Fourteen lambs with known birth dates were studied. They were composed of two groups: seven newborn lambs (0-3 d old) and seven young lambs (10-14 d old). The lambs remained with their mothers until the day of the experiment.

Surgical preparation. All lambs were blindfolded and placed on a warming pad. After right femoral arterial and venous catheterization under local anesthesia, the lambs were anesthetized with $\alpha$-chloralose. The chloralose was completely dissolved in hot water and given by rapid i.v. injection at a dose of 30-40 $\mathrm{mg} / \mathrm{kg}$. A tracheostomy was performed to facilitate ventilation with a Baby Bird ventilator (Bird Corporation, Palm Springs, CA). Polyvinyl catheters were inserted into the left jugular vein and carotid artery. With the animal in the right lateral recumbent position, a left thoracotomy was performed. After ligation of the ductus arteriosus, the pericardium was incised and a polyvinyl catheter was placed in the left atrium via its appendage. This catheter was then connected to a Hewlett-Packard 1205 pressure transducer (Hewlett-Packard Co., Palo Alto, CA) positioned at the level of the left atrium. The carotid artery catheter was connected to a like transducer. A precalibrated micromanometer (Camino Labs, San Diego, CA) was then inserted into the proximal main pulmonary artery. An electromagnetic flow probe $(\mathrm{C}$ and $C$ Instruments) was placed around the main pulmonary artery and connected to a Statham 2202 (Gould Instruments, Oxnard, CA) flowmeter. The tip of the micromanometer was at or distal to the flow probe. The pericardium was left open. Pancuronium bromide $(0.1 \mathrm{mg} / \mathrm{kg})$ was administered i.v. and the lambs were then allowed to stabilize for approximately 30 min before performing experimental maneuvers. At the end of each study, the anesthetized lamb was killed with i.v. potassium chloride.

Hemodynamic measurements and experimental protocol. Throughout the experiment, we continuously measured mean and phasic pulmonary and systemic arterial pressure, left atrial pressure, pulmonary arterial flow, and heart rate. These were displayed on a calibrated chart recorder (Gould 2200S) and recorded on a multichannel instrumentation tape recorder (Kyowa-Dengyo RTP-660). Arterial blood gas values were measured during each experimental state and after each ventilator change using a blood gas analyzer (Radiometer, Copenhagen, Denmark) set at $39.5^{\circ} \mathrm{C}$. Measurements of each experimental state were obtained when the lamb was considered to be in a steady state. Pulmonary vascular resistance was calculated by subtracting left atrial pressure from mean pulmonary arterial pressure and dividing by the flow. Systemic vascular input resistance was calculated by dividing the mean systemic pressure by the flow. 
After measurements of experimental variables were obtained in the normoxic state for purposes of establishing the stability and normality of the preparation (Table 1), alveolar hypoxia was administered (0.09-0.12 fraction of inspired oxygen via ventilator) to achieve an arterial $\mathrm{O}_{2}$ tension of 20-30 torr. A set of measurements was made, after which the animal was returned to the normoxic state. SNP was then infused at a dose of $4 \mu \mathrm{g} /$ $\mathrm{kg} / \mathrm{min}$, followed by addition of hypoxia and then dopamine at a dose of $10 \mu \mathrm{g} / \mathrm{kg} / \mathrm{min}$. A control group of lambs undergoing repeated exposure to hypoxia was not used, as experience in our laboratory has shown that subsequent responses to hypoxia generally do not differ from the initial hypoxic response in whole animal preparations. Hemodynamic and blood gas measurements were recorded with each state, and all animals underwent the experimental states in the same order.

Data analysis. Results are expressed as mean \pm 1 SEM. Differences between experimental states within the groups of newborn and young lambs were assessed using multiple $t$ tests for paired data. The significance of an individual $t$ test was chosen at a $p<0.025$ utilizing the Bonferroni correction to adjust the overall rate of significance to 0.05 for two consecutive comparisons: 1) the hypoxic baseline state versus the hypoxia plus SNP state and 2) the hypoxia plus SNP state versus the hypoxia plus SNP plus dopamine state. The different responses of the newborn and young lambs were analyzed by a multivariate comparison of the paired within group differences using Hotelling's $\mathrm{T}^{2}(4)$. A $p$ value of $<0.05$ was considered statistically significant for these comparisons.

\section{RESULTS}

Newborn lambs weighed $4.8 \pm 0.3 \mathrm{~kg}$ and young lambs weighed $7.1 \pm 1.0 \mathrm{~kg}$. Arterial blood gas values did not change significantly during drug infusions in either group (Table 2).

When hypoxemic newborn lambs were given SNP, the pulmonary blood flow decreased significantly from $238 \pm 10$ to 189 $\pm 19 \mathrm{~mL} / \mathrm{kg} / \mathrm{min}(p<0.005)$, as shown in Figure 1 . When dopamine was added, flow increased significantly to $227 \pm 24$ $\mathrm{mL} / \mathrm{kg} / \mathrm{min}(p<0.025)$, similar to the hypoxic baseline flow. However, when SNP was given to young lambs, pulmonary

Table 1. Normoxic data in newborn and young lambs*

\begin{tabular}{lcc}
\hline & Newborn & Young \\
\hline $\mathrm{Q}\left(\mathrm{mL} \cdot \mathrm{min}^{-1} \cdot \mathrm{kg}^{-1}\right)$ & $199 \pm 12$ & $152 \pm 11$ \\
$\mathrm{P}_{\mathrm{PA}}(\mathrm{mm} \mathrm{Hg})$ & $22 \pm 1$ & $16 \pm 1$ \\
$\mathrm{P}_{\mathrm{SYS}}(\mathrm{mm} \mathrm{Hg})$ & $84 \pm 4$ & $78 \pm 7$ \\
$\mathrm{PVR}\left(\mathrm{kPa} \cdot \mathrm{L}^{-1} \cdot \mathrm{min}^{-1} \cdot \mathrm{kg}^{-1}\right) \dagger$ & $14.8 \pm 1.1$ & $13.5 \pm 1.1$ \\
$\mathrm{SVR}\left(\mathrm{kPa} \cdot \mathrm{L}^{-1} \cdot \mathrm{min}^{-1} \cdot \mathrm{kg}^{-1}\right) \dagger$ & $57.1 \pm 3.7$ & $72.2 \pm 8.3$ \\
$\mathrm{HR}(\mathrm{bpm})$ & $191 \pm 10$ & $176 \pm 16$ \\
\hline
\end{tabular}

${ }^{*} \mathrm{Q}$, flow; $\mathrm{P}_{\mathrm{PA}}$, pulmonary arterial pressure; $\mathrm{P}_{\mathrm{SYS}}$, systemic vascular resistance; PVR, pulmonary vascular resistance; SVR, systemic vascular resistance; $H R$, heart rate.

$\dagger \mathrm{kPa}=0.1333 \mathrm{~mm} \mathrm{Hg}$. blood flow did not change significantly. With the addition of dopamine, flow trended upward from $172 \pm 26$ to $225 \pm 24 \mathrm{~mL} /$ $\mathrm{kg} / \mathrm{min}(p=0.03)$ to a value above hypoxic baseline.

Both groups of lambs approximately doubled their pulmonary arterial pressure in response to alveolar hypoxia to give us our initial experimental state (Fig. 2), with newborn lambs increasing from $22 \pm 1$ to $45 \pm 3 \mathrm{~mm} \mathrm{Hg}$ and young lambs increasing from $16 \pm 1$ to $31 \pm 2 \mathrm{~mm} \mathrm{Hg}$. When SNP was given to hypoxemic newborn lambs, pulmonary arterial pressure fell from $45 \pm 3$ to $34 \pm 2 \mathrm{~mm} \mathrm{Hg}(p<0.025)$. Similarly, when hypoxemic young lambs were given SNP, pulmonary arterial pressure also decreased significantly from $31 \pm 2$ to $22 \pm 2 \mathrm{~mm} \mathrm{Hg}(p<0.005)$. The addition of dopamine resulted in no significant change in pulmonary arterial pressure in either group of lambs.

When SNP was given to hypoxemic newborn lambs, both pulmonary arterial pressure and flow decreased proportionately, resulting in no significant change in the calculated pulmonary vascular resistance (Fig. 3). There was also no change in pulmonary vascular resistance with the addition of dopamine. However, pulmonary vascular resistance decreased significantly when SNP was added to hypoxia in young lambs, from $23.9 \pm 2.3$ to 18.7 $\pm 3.1 \mathrm{kPa} \cdot \mathrm{L}^{-1} \cdot \mathrm{min}^{-1} \cdot \mathrm{kg}^{-1}\left(179 \pm 17\right.$ to $140 \pm 23 \mathrm{~mm} \mathrm{Hg} \cdot \mathrm{L}^{-1}$. $\left.\min ^{-1} \cdot \mathrm{kg}^{-1}\right)(p<0.005)$. When dopamine was added, the pulmonary vascular resistance trended downward, although this was not statistically significant.

Systemic arterial pressure decreased significantly in both groups of lambs when SNP was combined with hypoxia (Fig. 4), dropping from $89 \pm 7$ to $64 \pm 8 \mathrm{~mm} \mathrm{Hg}$ in newborn lambs $(p<$ 0.005 ) and from $69 \pm 6$ to $54 \pm 4 \mathrm{~mm} \mathrm{Hg}$ in young lambs $(p<0.025)$. Adding dopamine at $10 \mu \mathrm{g} / \mathrm{kg} / \mathrm{min}$ did not change systemic arterial pressure significantly in either group.

Systemic vascular resistance did not change significantly in either group of lambs when SNP was added to hypoxia, although there was a downward trend noted in the young lambs that was not statistically significant (Fig. 5). When dopamine was added to SNP and hypoxia, the systemic vascular resistance actually decreased significantly in the newborn lambs from $45.6 \pm 4.0$ to $34.9 \pm 3.1 \mathrm{kPa} \cdot \mathrm{L}^{-1} \cdot \mathrm{min}^{-1} \cdot \mathrm{kg}^{-1}(344 \pm 30$ to $262 \pm 23 \mathrm{~mm} \mathrm{Hg}$. $\left.\mathrm{L}^{-1} \cdot \mathrm{min}^{-1} \cdot \mathrm{kg}^{-1}\right)(p<0.001)$, and trended downward from 48.4 \pm 8.9 to $33.9 \pm 4.3 \mathrm{kPa} \cdot \mathrm{L}^{-1} \cdot \mathrm{min}^{-1} \cdot \mathrm{kg}^{-1}(363 \pm 67$ to $254 \pm 32$ $\left.\mathrm{mm} \mathrm{Hg} \cdot \mathrm{L}^{-1} \cdot \mathrm{min}^{-1} \cdot \mathrm{kg}^{-1}\right)$ in the young lambs $(p=0.05)$.

Heart rate in both groups of lambs increased in response to hypoxia. The newborn lambs did not show significant heart rate changes with the experimental manipulations, as shown by heart rates of $229 \pm 15 \mathrm{bpm}$ during hypoxia, $207 \pm 15 \mathrm{bpm}$ during the state of hypoxia plus SNP, and $219 \pm 16 \mathrm{bpm}$ during the state of hypoxia plus SNP plus dopamine. Heart rate in the young lamb group did not change when SNP was added to hypoxia $(190 \pm 16$ versus $189 \pm 12 \mathrm{bpm})$, brat trended upward to $226 \pm 18 \mathrm{bpm}$ when dopamine was added to hypoxia plus SNP $(p=0.04)$. Left atrial pressure remained constant in the newborn lambs during the experimental states. Variable left atrial pressure responses were observed in the young lambs, none of which were statistically significant.

Table 2. Arterial blood gas data obtained during normoxic and experimental states*

\begin{tabular}{lccc}
\hline & $\mathrm{pH}$ & $\mathrm{PaCO}_{2}(\mathrm{kPa}) \dagger$ & $\mathrm{PaO}_{2}(\mathrm{kPa}) \dagger$ \\
\hline Newborn & & & \\
Normoxia & $7.37 \pm 0.02$ & $4.93 \pm 0.3$ & $21.6 \pm 1.5$ \\
HYP & $7.38 \pm 0.03$ & $4.93 \pm 0.3$ & $3.87 \pm 0.3$ \\
HYP \pm SNP & $7.37 \pm 0.03$ & $4.53 \pm 0.3$ & $3.60 \pm 0.2$ \\
HYP + SNP + D & $7.33 \pm 0.04$ & $4.80 \pm 0.4$ & $3.33 \pm 0.2$ \\
Young & & & \\
Normoxia & $7.40 \pm 0.01$ & $4.53 \pm 0.1$ & $20.1 \pm 1.2$ \\
HYP & $7.42 \pm 0.01$ & $4.80 \pm 0.2$ & $3.33 \pm 0.3$ \\
HYP + SNP & $7.43 \pm 0.02$ & $4.53 \pm 0.2$ & $3.47 \pm 0.4$ \\
HYP + SNP + D & $7.33 \pm 0.04$ & $4.80 \pm 0.3$ & $3.07 \pm 0.2$ \\
\hline
\end{tabular}

\footnotetext{
* $\mathrm{PaCO}_{2}$, arterial $\mathrm{CO}_{2}$ tension; $\mathrm{PaO}_{2}$, arterial $\mathrm{O}_{2}$ tension; $\mathrm{HYP}$, hypoxia; $\mathrm{D}$, dopamine.
}

$\dagger \mathrm{kPa}=0.133 \mathrm{~mm} \mathrm{Hg}$. 


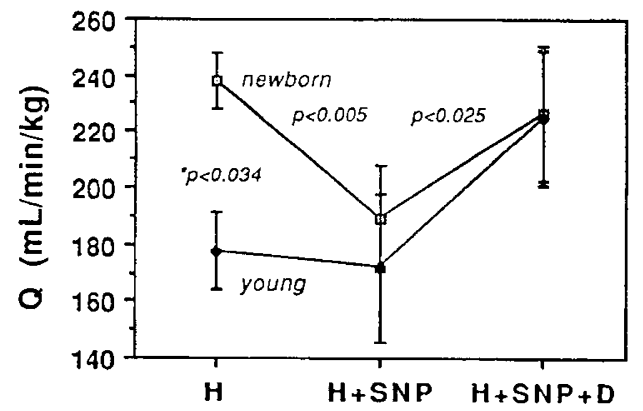

Fig. 1. Pulmonary blood flow $(Q)$ in newborn and young lambs during hypoxia $(H)$, hypoxia plus nitroprusside $(H+S N P)$, and hypoxia plus nitroprusside plus dopamine $(H+S N P+D) .{ }^{*}$, Difference between groups using Hotelling's $\mathrm{T}^{2}$.

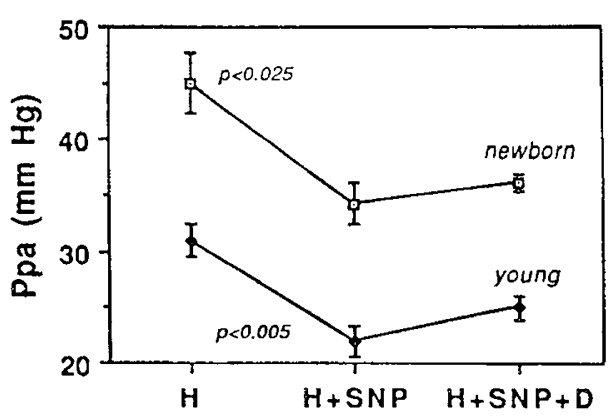

Fig. 2. Pulmonary arterial pressure $(P p a)$ in newborn and young lambs during hypoxia $(H)$, hypoxia plus nitroprusside $(H+S N P)$, and hypoxia plus nitroprusside plus dopamine $(H+S N P+D)$.

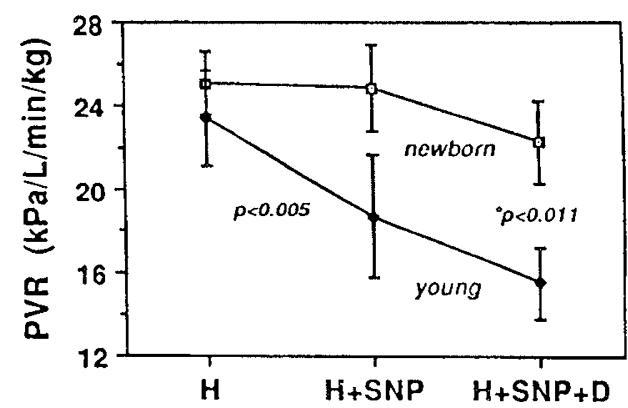

Fig. 3. Pulmonary vascular resistance $(P V R)$ in newborn and young lambs during hypoxia $(H)$, hypoxia plus nitroprusside $(H+S N P)$, and hypoxia plus nitroprusside plus dopamine $(H+S N P+D) .{ }^{*}$, Difference between groups using Hotelling's $\mathrm{T}^{2}$.

When comparing the responses of the two different age groups of lambs, the $21 \%$ decrease in pulmonary blood flow (cardiac output) produced by SNP in the hypoxemic newborn lambs was significantly greater than the $2 \%$ decrease seen in the young lambs $(p<0.034)$ (Fig. 1). In addition, the $22 \%$ decrease in pulmonary vascular resistence in the hypoxemic young lambs in response to SNP was significantly greater than the $0 \%$ change in the newborn lambs $(p<0.011)$ (Fig. 3).

\section{DISCUSSION}

We found significant age-related differences in the cardiovascular responses of newborn and young lambs to the nitrovasodilator SNP. Different patterns of pulmonary vascular response occurred at different ages. When nitroprusside was administered to hypoxemic young lambs, the pulmonary arterial pressure decreased in the presence of constant flow, supporting the conclusion that pulmonary vascular resistance decreased. Conversely, when hypoxemic newborn lambs were given nitroprusside, the decreases in pulmonary arterial pressure and flow were

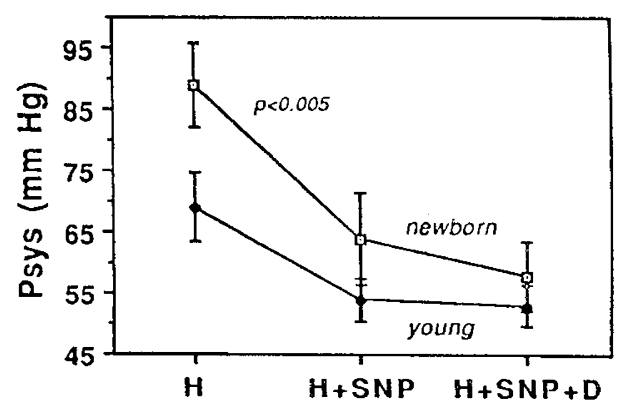

Fig. 4. Systemic arterial pressure (Psys) in newborn and young lambs during hypoxia $(H)$, hypoxia plus nitroprusside $(H+S N P)$, and hypoxia plus nitroprusside plus dopamine $(H+S N P+D)$.

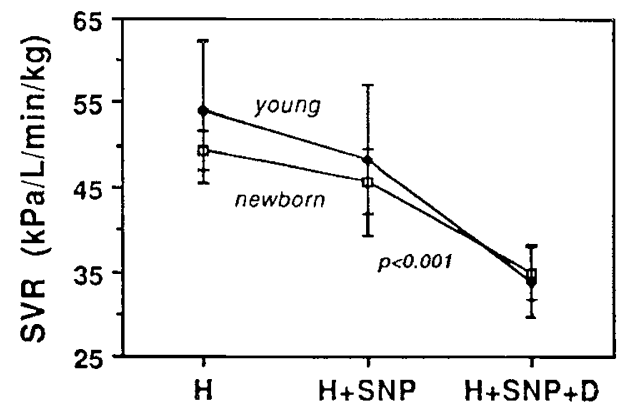

Fig. 5. Systemic vascular resistance $(S V R)$ in newborn and young lambs during hypoxia $(H)$, hypoxia plus nitroprusside $(H+S N P)$, and hypoxia plus nitroprusside plus dopamine $(H+S N P+D)$.

of similar magnitude (21-24\%), supporting the conclusion that pulmonary vascular resistance was unaffected. Our findings suggest that the pulmonary vasculature in the young lamb responds to nitrovasodilators with vasodilation or recruitment, whereas that in newborn lambs is refractory to these agents. Also, cardiac output dropped in the hypoxemic newborn lambs in response to nitroprusside, whereas the young lambs were able to maintain their cardiac output. Because heart rate and afterload did not change in the newborn lambs and nitroprusside does not alter contractility (5), it may be that the newborn lambs were unable to tolerate the decrease in preload resulting from nitroprussideinduced venous pooling (5).

Our observations raise important questions regarding agerelated differences in response not only to nitrovasodilators but also to other agents commonly studied in the newborn and young animal. Other studies have documented age-dependent effects of histamine (6), prostaglandin $\mathrm{D}_{2}(7)$, dopamine (8), and catecholamines (9) in animals. However, interpretation of other data is sometimes difficult because animals classified as newborns may actually be older than true newborns. Age-related differences have also been noted with a substance released from vascular endothelial cells, EDRF (10). At least one form of EDRF has been identified as nitric oxide (11-13), which activates guanylate cyclase, leading to an increase in cyclic $\operatorname{GMP}(14,15)$ and resulting in smooth muscle relaxation. Nitroprusside is also thought to act via cyclic GMP (16); thus, nitroprusside and EDRF appear to induce vasodilation by similar mechanisms. It has also been noted in isolated piglet arteries that vascular relaxation after nitric oxide was less at age $3 \mathrm{~d}$ than at age $10 \mathrm{~d}$, whereas no differences in response to nitroprusside were observed (10). This suggests that some animal species may undergo a maturational process in smooth muscle responsivity to various nitrovasodilators, which may explain the differences in pulmonary vascular response that we observed in our newborn and young lambs.

There are limited data in the literature regarding the effects of nitroprusside on the pulmonary circulation of young animals. In addition, we found no reported data on the effects of nitroprus- 
side on lambs as young as our newborn group of 0-3 d. However, several studies describe the cardiovascular effects in slightly older lambs. Mirro et al. (17) studied the effects of nitroprusside on systemic blood flow and oxyen delivery in hypoxemic conscious lambs at age 5-7 d. They found, as we did in our newborn lambs, that cardiac output and systemic arterial pressure decreased in each of the lambs; however, the decrease in cardiac output was not statistically significant, possibly because of large variability and slightly older age. They noted that the combination of nitroprusside and hypoxia caused decreased oxygen delivery to the brain, kidney, and carcass. During their study, the metabolites of nitroprusside were measured, showing undetectable levels of cyanide and nontoxic levels of thiocyanate. This suggests that our findings were not secondary to accumulated toxic metabolites of nitroprusside. Kuipers et al. (18) assessed the effects of nitroprusside on cardiac function and blood flow distribution in conscious normoxic 1- and 3-wk-old lambs. As in our study of 10- to 14-d-old lambs, they found an initial significant decrease in mean aortic blood pressure in both groups of lambs; however, they then noted a gradual increase such that after $50 \mathrm{~min}$ of nitroprusside infusion the blood pressure in the 1-wk-old lambs was not significantly different from control. They also noted a fall in cardiac output that was not statistically significant. These differences may be explained by the fact that they used conscious normoxic lambs as opposed to our anesthetized and paralyzed hypoxic lambs, and their youngest group was older than our newborn group. The acute drop in aortic blood pressure may also have activated a neurohormonal pathway such as the reninangiotensin system, thus allowing recovery of the blood pressure (19). We used an acute preparation during which the young lambs became acidemic when subjected to prolonged hypoxia. Thus, we were not able to follow the measurements of each experimental state for a prolonged period to assess whether adaptation would occur. Toorop et al. (20) studied the effects of nitroprusside in three groups of conscious lambs aged 11-88 d with and without aortopulmonary shunts. In their youngest group of control lambs, pulmonary vascular resistance trended downward with the administration of nitroprusside, but this was not statistically significant. Although they found no age-related difference in the lambs' responses, there were no newborn lambs in their study. Because of possible early adaptation or maturational changes, caution should be exercised when extrapolating from data obtained from older animals improperly defined as newborns.

In contrast to nitroprusside, we found no age-related differences in the response to dopamine in the presence of hypoxia and nitroprusside. We did find that when dopamine was added to nitroprusside, there was evidence only of $\beta$-adrenergic effect; that is, right heart output increased in both groups of animals but systemic arterial pressure did not change. It is possible that the nitroprusside masked the $\alpha$-adrenergic effect of dopamine, as has previously been described $(21,22)$, or that the dose of dopamine used was insufficient to achieve an $\alpha$-adrenergic effect in this species. Previous studies in lambs have shown an increase in systemic arterial pressure at $20 \mu \mathrm{g} / \mathrm{kg} / \mathrm{min}$ but not at $5 \mu \mathrm{g} / \mathrm{kg} /$ $\min (23,24)$, and we used an intermediate dose of $10 \mu \mathrm{g} / \mathrm{kg} /$ min. Indeed, additional work in our laboratory showed that the administration of dopamine at $10 \mu \mathrm{g} / \mathrm{kg} / \mathrm{min}$ to hypoxic lambs increased flow but did not raise systemic arterial pressure significantly. Further studies using higher dopamine doses are required to define the interaction between nitroprusside and dopamine. The downward trend in the young lambs' $\mathrm{pH}$ with the addition of dopamine (Table 2), although not statistically or clinically significant, was most likely secondary to prolonged hypoxemia.

We routinely use chloralose anesthesia because of the reported minor effects on cardiovascular reflexes in animals $(25,26)$. Interestingly, a recent report by Covert et al. (27) described increased heart rate, systemic vascular resistance, and pulmonary vascular resistance when chloralose was given to chronically instrumented lambs aged 4-22 d. We do not have hemodynamic measurements in our unanesthetized lambs for comparison. However, because we used each animal as its own control, we do not believe that chloralose affected our age-related findings.

Clinically, nitroprusside is sometimes used in hypoxemic neonates with persistent pulmonary hypertension of the newborn. If human newborns respond to nitrovasodilators in a similar fashion to the anesthetized lambs that we studied, administration of nitroprusside to hypoxemic human neonates may cause an undesirable fall in cardiac output without achieving the desired pulmonary vasodilation.

Because nitroprusside is known to act independently of vascular endothelium (16), we speculate that maturation of pulmonary smooth muscle responsiveness to nitrovasodilators may explain the age-related differences found in our study. We further speculate that administration of nitroprusside to hypoxemic human infants may cause unpredictable clinical responses as a result of variability in maturational processes.

\section{REFERENCES}

1. Turmen T, Davis JM, Aranda JV 1980 Sodium nitroprusside and RDSprimum non nocere. Arch Dis Child 55:82-83

2. Benitz WE, Malachowski N, Cohen RS, Stevenson DK, Ariagno RI, Sunshine P 1985 Use of sodium nitroprusside in neonates: efficacy and safety. J Pediatr 106:102-110

3. Abbott TR, Rees GJ, Dickinson D, Reynolds G, Lord D 1978 Sodium nitroprusside in idiopathic respiratory distress syndrome. [letter] $\mathrm{Br}$ Med J $1: 1113$

4. Johnson RA, Wichern DW 1982 Comparison of several multivariate means. In: Applied Multivariate Statistical Analysis. Prentice-Hall, Englewood Cliffs, pp 226-289

5. Gmeiner R, Riedl J, Baumgartner H 1975 Effect of sodium nitroprusside on myocardial performance and venous tone. Eur J Pharmacol 31:287-291

6. Goetzman BW, Milstein JM 1980 Pulmonary vascular histamine receptors in newborn and young lambs. J Appl Physiol 49:380-385

7. Cassin S, Tod M, Philips J, Frisinger J, Jordan J, Gibbs C 1981 Effects of prostaglandin $\mathrm{D}_{2}$ on perinatal circulation. Am J Physiol $240: \mathrm{H} 755-\mathrm{H} 760$

8. Gootman N, Buckley PM, Gootman PM, Nagelberg JS 1982 Age-related effects of single injections of dopamine on cardiovascular function in developing swine. Dev Pharmacol Ther 4:139-150

9. Buckley NM, Gootman PM, Yellin EL, Brazeau P 1979 Age-related cardiovascular effects of catecholamines in anesthetized piglets. Circ Res 45:282292

10. Zellers TM, Vanhoutte PM 1989 Augmentation of endothelium-dependent responses with maturation of piglet pulmonary arteries. Pediatr Res 25:246A(abstr)

11. Palmer RMJ, Ferrige AG, Moncada S 1987 Nitric oxide accounts for the biologic activity of endothelium-derived relaxing factor. Nature 327:524526

12. Ignarro LJ, Buga GM, Wood KS, Byrns RE, Chaudhuri G 1987 Endotheliumderived relaxing factor produced and released from artery and vein is nitric oxide. Proc Natl Acad Sci USA 84:9265-9269

13. Hutchinson PJA, Palmer RMJ, Moncada S 1987 Comparative pharmacology of EDRF and nitric oxide on vascular strips. Eur J Pharmacol 141:445-451

14. Vanhoutte PM 1987 The end of the quest? Nature 327:459-460

15. Furchgott RF 1984 The role of endothelium in the responses of vascular smooth muscle to drugs. Annu Rev Pharmacol Toxicol 24:175-197

16. Rappoport RM, Murad F 1983 Endothelium-dependent and nitrovasodilatorinduced relaxation of vascular smooth muscle: role of cyclic GMP. J Cyclic Nucleotide Protein Phosphor Res 9:281-296

17. Mirro R, Milley JR, Holzman IR 1985 The effects of sodium nitroprusside on blood flow and oxygen delivery to the organs of the hypoxemic newborn lamb. Pediatr Res 19:15-18

18. Kuipers JRG, Sidi D, Heymann MA, Rudolph AM 1984 Effects of nitroprusside on cardiac function, blood flow distribution, and oxygen consumption in the conscious young lamb. Pediatr Res 18:618-626

19. Pipkin FB, Lumbers ER, Mott JC 1974 Factors influencing plasma renin and angiotensin II in the conscious pregnant ewe and its foetus. $J$ Physiol 243:619-636

20. Toorop GP, Hardjowijono R, Koers JH, Van Straalen MJ, Wildevuur CRH, Zijlstra WG, Kuipers JRG 1989 Circulatory effects of sodium nitroprusside in the conscious lamb with an aortopulmonary left to right shunt. Pediatr Res 25:44-48

21. Hsieh YY, Goldberg LI 1979 Hemodynamic consequences of administration 
of phentolamine or nitroprusside with dopamine in the dog. J Cardiovasc Pharmacol 1:379-388

22. Bixler TJ, Gott VL, Gardner TJ 1981 Reversal of experimental pulmonary hypertension with sodium nitroprusside. J Thorac Cardiovasc Surg 81:537545

23. Feltes TF, Hansen TN, Martin CG, LeBlanc AL, Smith S, Giesler ME 1987 The effects of dopamine infusion on regional blood flow in newborn lambs. Pediatr Res 21:131-136

24. Strobel GE, Wollman H i 969 Pharmacology of anesthetic agents. Fed Proc 28:1386-1403
25. Greisheimer EM 1965 The circulatory effects of anesthetics. In: Hamilton WF (ed) Handbook of Physiology-Circulation. Williams \& Wilkins, Baltimore, pp 2483-2485

26. Covert RF, Drummond WH, Gimotty PA 1988 Chloralose alters circulatory response to $\alpha$-receptor stimulation and blockade. Am J Physiol 255:H419$\mathrm{H} 425$

27. Covert RF, Drummond WH, Gimotty PA, Carter RL 1989 Chloralose alters both basal hemodynamics and cardiovascular responses to alveolar hypoxia in chronically instrumented, spontaneously breathing lambs. Pediatr Res 25:389-395

\section{Announcement}

\section{Annual Meetings}

The American Pediatric Society, The Society for Pediatric Research, and The Ambulatory Pediatric Association will hold their annual meetings April 28-May 2, 1991 at the New Orleans Hilton and Rivergate Convention Center, New Orleans, LA. For further information, contact: APS/SPR Association Headquarters, 2650 Yale Blvd., S.E., Suite 104, Albuquerque, NM 87106, (505)764-9099, FAX (505)842-8227 or Ambulatory Pediatric Association, 6728 Old McLean Village, McLean, VA 22101, (703)556-9222. 